\title{
A central issue of teaching within the hydroinformatics paradigm
}

\author{
M.B. Abbott \\ International Institute for Hydraulic and Environmental Engineering \\ P.O. Box 3015, 2601 DA Delft, The Netherlands
}

The principal task of the hydraulics of the next millennium is to save our planet from environmental cataclysm; and, quite consentaneously, the word "cataclysm" itself derives from " a rush of water ". Hydraulics can only succeed in this task when it avails itself of all that modern information technology provides, and so, in the first place, when it makes proper use of digital computers. Hydraulics can obly avail itself of modern information technology, however, when it has a proper understanding of this technology and the relation of such technology to the aquatic environment. The name of this area of understanding is hydroinformatics. It follows that the teaching of hydroinformatics will be essential to hydraulic engineering education in the next millenium. One central issue that arises in this teaching is discussed here.

\section{Introduction}

Already today, in our own time, man has ceased to face his outer world supported only by his unaided intellect ; already today man faces this world as one who has entered into a symbiotic relation with his own most fantastic creation, his digital computer. I recall only too clearly how, when I predicted that something like this would happen some twenty years ago, my audience tittered with embarrassment; today, however, such a statement has become commonplace, if not actually platitudinous.

A digital computer is a device for processing information, and most of us already live in societies where the processing of information is the principal social occupation, employing directly more persons than any of agriculture, trade, or manufacturing. Just as we have in earlier times identified agricultural, mercantile and industrial societies by the preponderant role of a particular type of employment in them, so most of us today indentify our current society as an informational society. Similarly, just as each of these types of society can be said to have been established by a revolution (and we may here think especially of the industrial revolution of the 18th and 19th centuries), so we nowadays speak of an informational revolution, as that which establishes an informational society. Once again, and again quite consentaneously, just as we associate one of our most significant agricultural revolu- tions with deep ploughing, using an iron plough, our most significant mercantile revolution with the magnetic compass and the chronometer, and our culminating industrial revolution with the steam engine, so we associate our current informational revolution with the digital machine.

This symbiosis of man and digital machine nowadays extends to every aspect of human activity, so that it also extends to our own area of hydraulics. The hydraulician, he also, enters into a symbiotic relation with the digital machine, and it is in this symbiotic relation that he, in his turn, relates to society as a whole. A long time ago now, in 1969, I introduced the name of Computational Hydraulics to cover the symbiosis between hydraulics and digital computing, while I have more recently, in 1987, introduced the name of Hydroinformatics to cover the symbiosis between the hydraulician and information technology generally, as this relates in its turn to society as a whole (Abbott, 1979; Abbott, 1990d). Thus computational hydraulics is the science of the hydraulics of an informational society, while hydroinformatics is the technology of applying computational hydraulics within society.

(However whereas "computational hydraulics" has never translated at all well into French and German, "hydroinformatics " has done so from the very beginning — as " hydroinformatique " and " hydroinformatik » - ; so perhaps I am at least making some progress in this business of coining new names!)

LA HOUILLE BLANCHE/N 3/4-1991 


\section{About hydroinformatics}

In Abbott (1990d), the definition of hydroinformatics is advanced through four stages. The first of these, which is based primarily upon Heidegger's (1977) Question Concerning Technology, reads as follows:

"Hydroinformatics is the subject that treats all scientifically-defined information and information flows associated with $a$ water body in such a way that this body is regarded as a standing reserve for social use, so that it is subject to the interested actions of common-sense, heuristic rules and facts and their associated reasoning, as well as to all the required actions of ordering, counting and computing. "

The second definition, on the other hand, asserts something else again, which might be called the "primal influence of the numbers ". It is pointed out that almost everything that is decided nowadays is decided through the use of numerical models. From this, the proposition is advanced that: "The numbers have begun to function in another way. " This is not " another way " in any scientific sense, but in an essentially non-scientific, technological sense. Thence arises the definition :

"Hydroinformatics is the coming to presence in water technology of a new way of functioning of the numbers ; it is a new way of creativity, of formation, of activity in relation to the waters, realised through the intervention of the numbers; it is a new place where truth happens, between the waters and the numbers. "

The other two definitions will be introduced when concluding this piece. The principal immediate and pragmatic aspect is that hydroinformatics comprehends all applications of information technology to the aquatic environment. It is thus concerned with measuring and recording devices, including remote-sensing facilities, with data and knowledge structuring, coding and transmission, with a variety of kinds of buffer memory devices, with domain knowledge encapsulation (legal, contractual, hydraulic, hydrologic, quality parametric, etc...) in models, both of the logical and numerical varieties, with man-machine interfaces and other graphics facilities, and indeed every thing else of this kind. It is by no means restricted to simulations, but extends through the provision of adviceserving facilities to on-line control, safety, planning and maintenance systems. Its development is based on the premise that the engineer of the year 2000 will be a tool user on a very large scale. (It is estimated that in the year-2000 European-market-competitive environment, at least $100000 \mathrm{ECU}$ of tooling will be required for each engineer : see, for example, Abbott et al., 1991.) Moreover, engineering and other applied-science needs will necessitate a movement beyond the level of specific, stand-alone tools, to the provision of languages providing tool interaction, and thence the provision of complete working environments (Abbott, 1990a, b, c and d).

Hydroinformatics thus brings together both deducing and computing aspects of digital machine utilisation. Indeed, from a narrow, scientific-content point of view, hydroinformatics is composed by the union of artificial intelligence (AI) and computational hydraulics (CH). It follows, by way of example, that its mathematics must have a bias towards the study of recursion, whether this takes the forms of foreward and backward chaining in the inference engine of an expert system shell or it takes the form of foreward, backward and doubles-weep algorithmic structures in numerical modelling. As the general approach represented by this aspect of recursion is already well established in mathematical logic (e.g. Lightstone, 1978; Lyndon, 1964 ; Mendelson, 1964 ; Manin, 1977), while the way between this basis and AI has been set out by Genesereth and Nilsson (1988) and the way between it and computational hydraulics by Abbott and Basco (1989), it is clear at once that mathematical logic provides, together with its consort of set theory, the fundamental mathematical basis of the science of hydroinformatics.

\section{Mathematical foundations}

Modern science, as Heidegger in particular explained, is mathematical through and through, even when it is not cast explicitly in mathematical form. Correspondingly, few engineers are aware that they are using mathematics at every stage of their careers, even though they are not "writing equations». But then, given that mathematical education in engineering generally lags about one hundred years behind the research upon which it is based, it is quite easy to predict the mathematical-educational requirements of the hydraulic engineer of the year 2000 simply by referring back to the state of mathematical research in the year 1900 . This makes our task particularly simple, since at the International Congress of Mathematicians held in Paris in 1900, David Hilbert presented, on the 8th August, 23 problems which he believed would occupy mathematicians throughout the entire 20th century. A survey made in 1975 (Browder, 1976) demonstrated that Hilbert's estimate was correct in the case of mathematics per se, even as the perception of the nature of these problems appeared to have changed as the century progressed. However, over the period 1970-1990, some of these Hilbert problems have also come to influence technologies like hydraulics. It must suffice here to mention only the influences on hydraulics of the second of these Hilbert problems, but then in a little detail. Let us first state what this problem is.

Hilbert's second problem has to do nominally with the consistency of the axioms of arithmetic. Kreisel (1976) stated it in the form of a proposition :

"It should be possible to exploit the finiteness of (all) proofs and so establish the consistency of the axioms of arithmetic without the use of (familiar) infinite models; even though the theorems proved are ordinarily intended to be about infinite sets."

The attempt to realise this supposition, to demonstrate its general validity, came to be called " Hilbert's programme». It was the intention to demonstrate that the whole realm of mathematics could be constructed from out of a finite set of formal axioms using only finite sets of formallogical operations. In particular, it should by these 
means be deducible, or decidable, whether any given theorem was true or false. Correspondingly, in time, Hilbert's programme came to devolve upon the problem of establishing this possibility, so that it became a "problem of decidability", or Entscheidungsproblem. As in mathematical logic every problem of deducibility is mirrored by a problem of computibility (e.g. Manin, 1977), the Entscheidungsproblem could also be posed in terms of demonstrating the computability of any " function ", i.e. the existence of an algorithm for solving any given problem.

As is now rather widely known, Hilbert's programme was shown to be untenable, at least in its most general form, already by Gödel, in 1931. It suffices to recall here that in the proof of the first of the two theorems enunciated by Gödel at that time (see van Heijenoort, 1967, pp. 592617), it was demonstrated that within any consistent system of logic or mathematics generally that was rich enough to encompass arithmetic, statements could be made that could be neither proved nor disproved. Such statements could only be proved or disproved within a system that was richer in its axioms; but then within this system again statements could be found that could be neither proved nor disproved. Thus, as Heppenheimer (1990) has expressed the matter : "Gödel's work demonstrated limits to the ability of mathematics to answer questions in its own fields. "

Now from one point of view - which was for a long time the dominant point of view in mathematical logic Gödel's 1931 theorems concluded an epoch, which van Heijenoort characterised in one of " the arithmetisation of logic ». However, a central issue during this process of arithmetisation was that of the possibility of constructing and solving of logical polynomials which had solutions exclusively in the field of integral numbers. These are the so-called "diophantine equations". (This issue was posed independently as the tenth problem of Hilbert's 1900 list.) It was in fact shown by Matyasevich in 1970 (see Chaitin, 1987, and Heppenheimer, 1990) that there is no general procedure even for establishing the existence of solutions of such equations : any theory of diophantine equations will entail formally undecidable examples.

Perhaps better known nowadays is the posing of this problem in terms of an idealised computer known as a "Turing machine». We may in this case recall Turing's question of whether one could decide whether, for any arbitrary programme, this machine would run on indefinitely or come to a halt. Turing showed that this question is also undecidable : no general method can exist for determining whether any programme whatsoever will halt.

These problems, of diophantine analysis and general algorithmic halting, came together in a series of papers by Chaitin (e.g. 1982, 1987). In summing-up this work, Chaitin wrote (1987):

"In conclusion, we have seen that proving whether particular exponential diophantine equations have finitely or infinitely many solutions, is absolutely intractable. Such questions escape the power of mathematical reasoning. This is a region in which mathematical truth has no discernible structure or pattern and appears to be completely random. These questions are completely beyond the power of human reasoning. Mathematics cannot deal with them."

We might then observe, in passing, that this same conclusion appears to arise in the case of turbulent flows : the problem of determining the flow obtaining in the limit, as $\Delta x_{i} \rightarrow 0, i=1,2,3$, and $\Delta t \rightarrow 0$ appears also to be and undecidable problem (e.g. Abbott and Basco, 1989, p. 366).

\section{The number myth}

As we run out of the limits of the scientific, so we run into the realm of the mythical. This has been realised long ago in the area of quantum physics, and indeed Chaitin, Heppenheimer and other mathematicians have often drawn upon this earlier realisation. Thus, from the quantum-physical side, we may quote Finkelstein (1978, p. 99) : "We choose as symbols physical systems that behave predictably, and so symbols come close to having the aspects of eternity. Logos supposes a perfect match between symbolic processes and physical, like that once supposed between the laws of Newton and the planetary process. The logos is eternal, the process transient, but somehow they match.

"In mythos, which is older than logos, process, including our involvement in it, is primory, and symbols are a kind of demonstrative accompaniment, like chants accompanying ancient rites, declaring the rhythm and the values of the process but never defining it.

"The historic transition from mythos to logos seems part of a pre-Platonic passage from the oral to the written tradition. Today the tide reverses.

"If 17th century science evolves out of 16th century magic to minimize the mythical, romantic, illogical, and arbitrary in the world, then the greatest surprise of science must be that the actual world is to an overwhelming extent illogical, irrational and arbitrary. The illusion of rationality that fostered classical physics turns out to be the law of large numbers, which is not even a law in the sense of logos. Twentieth century psychoanalysis and quantum physics rediscover the enormous unperceived irrational content of the mental and physical process."

The understanding of the role of mythology in modern science has even entered the established tradition, as expressed in the Encyclopaedia Britanrica as follows (Vol. 13, p. 791) :

"Myth is that which is taken for granted when thought begins. It is at the same time the limit science reaches in its own course : certain elementary ideas or principles are found to be of such lucidity that no further definition can be undertaken. In recent scientific researches, especially in astronomy and biology, questions of teleology (final ends) have gained in importance, as distinct from earlier concerns with questions of origin. These recent concerns stimulate discussion about the limits of what can be scientifically explained, and they reveal anew a mythological dimension to human knowledge. It should be underlined that there are such mythological dimensions to science in the same way as there are to society." 
As I have discussed the number myth as this arises in computational hydraulics and hydroinformatics at length elsewhere (Abbott, 1989; Abbott and Basco, 1989; Abbott, 1990d), it must suffice here only to reiterate two of its aspects or manifestations. The first of these is that of numerical instability where, as described in Abbott and Basco (1989, p. 70 et seq) : " Instability is the numbers' way of telling us that our scheme contains contradictory statements. "

In the real world of numerical modelling it is this principle that sustains us in the greater part of our work, as we proceed to develop our models, and with these our modelling systems, by driving them to instability and then investigating the conceptual contradictions that trigger these instabilities. As explained more fully in Abbott (1990b), a statement of principle such as this is not a scientific statement : it can be neither demonstrated for all schemes nor proven from more immediate, or self-evident propositions. It is a statement borne of experience, through constant reiteration, so that it is a dogmatic statement, that is, a statement of a myth. It is conjectured, here and now, that the question of its general truth or falsity is undecidable.

In the same vein, the paradoxes that arise in computational hydraulics - to date: the stability paradox, the resolution paradox of weak solutions and the circulation paradox - are manifestations of the number myth. They serve as further metaphores for this myth.

The manifestations of the number myth cannot be restricted to the side of computability, however. We may also, as our second illustration, see their manifestations within studies of the limitations of symbolic paradigms in $\mathrm{AI}$, and particularly in the formulation and justification of subsymbolic paradigms, such as those currently realised using neural network machines and their emulators. The questions of the potentials and limitations of the respective paradigms can be reduced to (or « modelled » by) arithmetic questions, so that they also fall within the ambit of the number myth. This is also introduced in Abbott (1990d). The teleological question then arises quite generally of the ultimate purposes and aims of numerical modelling and logical modelling as the primary outer-world manifestations of productions of the number myth in our own times. As has there been argued (much along the lines of Jaspers and Bultmann, 1954), this myth, like all other myths, must be connected to the totality and unity of myths of theistic allegory. In my work I have connected this aim to what is currently called the " environmental " one, of protecting the natural, aquatic environment, the Leonardian " arteries and veins " of the biosphere, and in this I have followed Barth (1960). In general terms, the answer to the " teleological " question concerning modelling " provides the third definition of hydroinformatics, as follows (Abbott, 1990d): «Hydroinformatics is the coming to presence of the number myth as this supports us in our stewardship of the arteries and veins of the biosphere ". Then, in the more specific vocabulary of a (Barthian) Christian theology, this becomes, as a fourth definition: "Hydroinformatics is the means whereby the number myth strengthens the covenant between the Creator and His creature in the realms of the arteries and veins of the biosphere ".

\section{Conclusions}

Although the hydraulic engineer of the year 2000 may be relieved from many routine design and management tasks by advances in tools, languages and environments, this engineer will require a much deeper understanding of certain fundamental matters in order to make proper use of these facilities. In particular, a rather thorough grounding in mathematical logic and set theory will be required, probably with the emphasis upon the mathematical-logical side. These are, for example, foundational subjects in the International Course on Hydroinformatics, which is due to begin in Delft in October 1991. In view of what has been said above, it should be explained that it is not intended in the Delft course to teach diophantine analysis, while the discussions of undecidability will be restricted to those arising from the Turing problem. The symbolic paradigm side will be advanced roughly along the lines already set out by Genesereth and Nilsson (1988). The mathematicallogical distinctions between (first- and second-order) languages will similarly be used to initiate the computational-fluid-dynamic side, as set out by Abbott and Basco (1989). The limitations of both approaches in ecological modelling, including its anthropological aspects, will then be associated with limitations arising from the more fundamental assumptions, leading to the use of sybsymbolic paradigms, as introduced in Abbott (1990d).

Over and above all these matters, however, the engineer of the year 2000 will need some guidance and advice on the subject of mythology. The nature of mythology needs to be explained: its inevitability in all thinking about society and science, and indeed in thought generally, its forms or metaphores, its connections, teleologies and aeschatologies, its hermeneutics and its various exegeses; all of this needs to be introduced. The results of such as Dilthey, Husserl, Heidegger and Jaspers on the metaphysical side, and of such as Schleiermacher, Barth and Bultmann (with apologies for the Protestant bias!) on the other side (see Abbott, 1990d) need to be communicated. We dare not leave our young engineers as helpless « babes in the woods " when it comes to such critical and potentially dangerous matters as these. With such an understanding in place, on the other hand, the relation between man and his most fantastic creation, his digital machine, can transform from one of symbiosis to one of synergy. This is, of course, a necessary condition for facing the environmental challenges of the next century, and so for redressing the balance between the forces on the side of the creation and those opposing the creation, in the realms of the arteries and veins of the biosphere. It is really such a long way from the Ecole des Ponts et Chaussées, where these things are not currently taught, to the Ecole Normale Supérieure, where they presumably are (e.g. Derrida, 1982)? 


\section{Références}

Аввотт M.B., 1979. Computational hydraulics: elements of the theory of free-surface flows, Longman, London.

Аввотт M.B., 1989. "Modelling of the coastal environment ", in Falconer R.A., Goodwin P., Mathews R.G.S., editors, Proceedings of the International Conference on Hydraulic and Environmental Modelling of Coastal, Estuarial and River Waters, Gower, Aldershot.

Aввотт M.B., 1990a. "Numerical modelling for coastal and ocean engineering ", in Herbich J.B., editor, The handbook of ocean and coastal engineering, Gulf, Houston.

Aввотт M.B., 1990b. "Contributions of computational hydraulics to the foundation of a computational hydrology ", in Bowles D.S, and O'Connell P.E., editors, Recent advances in the modelling of hydrologic systems, Kluwer, Amsterdam.

AввотT M.B., 1990c. " The impact of ESPRIT projects upon the modelling of hydrologic systems" in Bowles D.S. and O'Connell P.E., editors, Recent advances in the modelling of hydrologic systems, Kluwer, Amsterdam.

Аввотт M.B., 1990d. Information technology and the aquatic environment: hydroinformatics, International Institute for Hydraulic and Environmental Engineering, Delft.

Aввотт M.B. and BASCO D.R., 1989. Computational fluid dynamics: an introduction for engineers, Longman, London, and Wiley. New York

Abbott M.B., Havnoe K., Lindberg S., 1991. "The fourth generation of numerical modelling in hydraulics ", submitted, J. Hyd. Res.

AввотT M.B. and MADSEN P.E., 1990. "Modelling of wave agitation in harbours $"$ in Hanes D.M. and Le Méhauté B. editors, The Sea Vol. 9, Wiley, New York.

BARTH K., 1960. Church dogmatics, Trans. Bromiley G.W. and Ehrlich R.J., Clark, Edinburgh.
Browder F.E. (editor), 1976. Proc. sym. pure math XXVIII. American Mathematical Society, Providence, Rhode Island.

Chaitin C.J., 1982. "Gödel's theorem and information ", Int. J. Theoretical Phys., 22, pp. 941-954.

ChaITIN C.J., 1987. "Incompleteness theorems for random reals ", Advances in applied math, 8, pp. 119-146.

DERRIDA J., 1982. Margins of philosophy, trans. Bass A., Harvester, London.

FINKELSTEIN D., 1978. "Beneath time : explorations in quantum topology " in Fraser J.T, et al., editors, Study of time III. Springer, New York.

Genesereth M.R. and Nilsson N.J., 1988. Logical foundations of artificial intelligence, Morgan Kaufmann, Palo Alto.

HeIdegGer M., 1971. The question concerning technology, trans. Lovit W, Harper and Row, New York.

HePpenheimer T.A., 1990. "The long shadow of Kurt Gödel ", MOSAIC 211 , National Science Foundation, Washington D.C.

VAN HeijenOort J., 1967. Editor, From Frege to Gödel : a source book in mathematical logic. Harvard Univ. Press, Cambridge, Mass.

JASPERS K. and Bultman R., 1954. Die Frage der Entmythologisierung. Piper, Munich.

KREISEL C., 1976, «What have we learnt from Hilbert's second problem " in Browder F.E. (above), pp. 93-130.

Lightstone A.H., 1978. Mathematical logic, an introduction to model theory, Plenum, New York.

Lyndon H.C., 1964. Notes on logic, von Nostrand, New York.

Manin Yu. 1., 1977. A course in mathematical logic, trans. Koblitz N., Springer, New York.

MENDELSON E., 1964. Introduction to mathematical logic, von Nostrand, New York. 